\title{
Pelvic floor function in multiple sclerosis
}

\author{
J S Jameson, J Rogers, Y W Chia, J J Misiewicz, M M Henry, M Swash
}

\begin{abstract}
The aim of this study was to define pelvic floor function in patients with multiple sclerosis and bowel dysfunction, either incontinence (MSI) or defecation difficulties without incontinence (MSC). Normal controls and patients with idiopathic neurogenic faecal incontinence without multiple sclerosis (FI, disease controls) were also studied. Thirty eight multiple sclerosis patients ( 20 incontinent, 18 incontinent) 73 normal controls, and 91 FI patients were studied. The FI group showed the characteristic combined sensorimotor deficit previously described in these patients of low resting and voluntary contraction anal pressures, increased sensory threshold to mucosal stimulation, and increased pudendal nerve terminal motor latencies and fibre densities. MSI patients had significantly lower anal resting pressures $\left(80(30-140) \mathrm{cm} \mathrm{H}_{2} \mathrm{O}\right.$, median (range) $v 98$ (30-200), normal controls, $\mathbf{p}=0.002$ ) and both MSC and MSI patients had significantly lower anal maximum voluntary contraction pressures $\left(65(0-260) \mathrm{cm} \mathrm{H}_{2} \mathrm{O}\right.$, MSC and 25 (0-100), MSI $v 120$ (30-300), normal controls, $p=<0.0004)$ and higher external anal sphincter fibre densities (1.7 $(1 \cdot 1-2 \cdot 6)$, MSC and 1.7 (1.1-2.4), MSI $v 1.5$ $(1 \cdot 1-1 \cdot 75)$, normal controls, $\mathrm{p}<0.006)$ compared with normal controls but pudendal nerve terminal motor latencies were similar and no sensory deficit was found. This contrasted with the idiopathic faecal incontinent patients who, in addition to significantly higher fibre densities $(1.8(1 \cdot 1-3), p=0.001)$ had increased pudendal latencies $(2.5(1.1-5.5) \mathrm{mS} v 2.08$ (1.4-2.6), $\mathrm{p}=0.001)$ compared with normal controls. The idiopathic faecal incontinent group had significantly lower resting anal pressures $\left(50(10-160) \mathrm{cm} \mathrm{H} \mathrm{H}_{2} \mathrm{O}, \mathrm{p}=0.02\right)$ than the MSI group. Comparison with the incontinent and continent multiple sclerosis groups showed that incontinence was associated with lower voluntary anal contraction pressures ( 25 $(0-100) v 65(0-260), p=0.03)$ but that there were no other differences between these two groups. Pelvic floor function is considerably disturbed in multiple sclerosis, showing muscular weakness with preservation of peripheral
\end{abstract}

TABLE I Patient characteristics

\begin{tabular}{lllll}
\hline & $\begin{array}{l}M S \\
\text { incontinent }\end{array}$ & $\begin{array}{l}\text { MS } \\
\text { continent }\end{array}$ & $\begin{array}{l}\text { Non-MS } \\
\text { incontinent }\end{array}$ & Controls \\
\hline Number & 20 & 18 & 91 & 73 \\
Median age, years (range) & $43(26-67)$ & $44(26-70)$ & $52(26-87)$ & $50(16-85)$ \\
Sex (M/F) & $8 / 12$ & $6 / 12$ & $11 / 80$ & $40 / 33$ \\
Parity (No of nulliparous women) & $3 / 12$ & $3 / 12$ & $11 / 80$ & $15 / 33$ \\
Mobility (wheelchair dependent/independent) & $7 / 13$ & $8 / 10$ & & \\
Duration of MS, years (range) & $7 \cdot 5(1 \cdot 5-18)$ & $9(1-30)$ & & \\
Urinary symptoms (yes/no) & $9 / 11$ & $8 / 10$ & & \\
\hline
\end{tabular}

MS=multiple sclerosis

motor nerve conduction, providing indirect evidence that this is mainly a result of lesions within the central nervous system.

(Gut 1994; 35: 388-390)

Multiple sclerosis is characterised by multiple demyelinating lesions within the central nervous system causing a variety of neurological symptoms, including disturbances of the urinary bladder and anorectal function. The former has received much attention in the past and it is recognised that urinary symptoms can be a presenting feature of multiple sclerosis. 'In contrast, bowel dysfunction has not been widely investigated and it has generally been held that the most significant problem in this respect is constipation and that faecal incontinence is comparatively rare. Recent studies, however, of bowel dysfunction in multiple sclerosis show that constipation was present in $43 \%$ of 280 unselected patients with multiple sclerosis, and $51 \%$ were faecally incontinent. ${ }^{2}$ This study aimed at investigating pelvic floor physiology in multiple sclerosis patients and comparing them with patients with faecal incontinence without multiple sclerosis and also with normal controls.

\section{Patients and methods}

Thirty eight patients (14 men) with a definite diagnosis of multiple sclerosis, ${ }^{3}$ referred from the ARMS Unit at the Central Middlesex Hospital were studied. The median duration of disease was eight years, (1-30 years, range), 17 had urinary symptoms, 23 were independently mobile most of the time, and 15 were wheelchair dependent. Twenty of these patients had been incontinent of solid stool at least once in the three months before their referral and most experienced this symptom once a week (MSI). The remaining 18 had difficulty with evacuation and had never been incontinent of stool (MSC). The disease control group consisted of 91 patients with idiopathic neurogenic faecal incontinence to solid stool occurring at least once in the three months before investigation, most patients having episodes at least once a week (FI). Seventy three healthy volunteers were also studied, recruited from inpatients without anorectal symptoms, or from staff of the hospital. Table I shows the characteristics of these four study populations.

Pelvic floor function was assessed by anorectal manometry using a water filled microballoon and a station pull through technique to measure functional anal canal length, maximum sphincter pressure at rest, and maximum voluntary contraction pressure. Anorectal sensation was assessed with a slowly inflated air filled balloon to measure the threshold of sensation, the volume at which the urge to defecate was perceived, and 
the maximum tolerated volume. Mucosal sensitivity was assessed in the rectum and middle third of the anal canal using a bipolar ring electrode mounted on a Foley catheter connected to a constant current stimulator. Right and left pudendal nerve terminal motor latencies were measured with a pudendal stimulating electrode ${ }^{4}$ to calculate a mean value. The fibre density in the external anal sphincter was measured using a single fibre electromyographic needle and standard electromyographic settings. ${ }^{5}$

\section{ANALYSIS OF RESULTS}

Results for each of the variables recorded above were compared between the incontinent multiple sclerosis patients (MSI) and the nonmultiple sclerosis incontinent patients (FI) and the controls using the Mann-Whitney test, (SPSS/PC+, Statistical Software Package). The continent multiple sclerosis patients (MSC) were compared with the controls and the continent and incontinent multiple sclerosis patients were compared with each other. To control for the effects of childbirth, a separate analysis using the same intergroup comparisons was also made excluding parous women. There were 98 nulliparous subjects in the study (11 MSI, 9 MSC, 23 FI, 55 normal controls).

\section{Results}

Analysis of the whole study population confirmed that the faecally incontinent, nonmultiple sclerosis group had a combined sensorimotor pudendal neuropathy when compared with the normal controls, as has previously been described..$^{6-8}$ No differences between any of the groups were found when considering functional anal canal length and sensation to the air filled balloon. Table II gives

TABLE II Results of resting pressure (RP), voluntary contraction pressure $(V C P)$, pudendal latencies (PNTML), anal canal $(A S)$ and rectal sensation $(R S)$ in multiple sclerosis (incontinent, MSI and continent, MSC), faecal incontinence without $M S(F I)$ and normal controls $(N C)$ (median (range))

\begin{tabular}{|c|c|c|c|c|c|}
\hline & $M S I$ & $M S C$ & $F I$ & $N C$ & $p$ \\
\hline $\begin{array}{l}\text { Number } \\
\mathrm{RP}\left(\mathrm{cm} \mathrm{H} \mathrm{H}_{2} \mathrm{O}\right)\end{array}$ & $\begin{array}{l}20 \\
80(30-140)^{\star} \dagger\end{array}$ & $\begin{array}{l}18 \\
80(30-140)\end{array}$ & $\begin{array}{l}91 \\
50(10-160) \dagger\end{array}$ & $\begin{array}{l}73 \\
98(30-200)^{\star}\end{array}$ & $\begin{array}{l}{ }^{\star} 0.002 \\
+0.02\end{array}$ \\
\hline $\operatorname{VCP}\left(\mathrm{cm} \mathrm{H}_{2} \mathrm{O}\right)$ & $25(0-100)^{\star} \Phi$ & $65(0-260) \mp \emptyset$ & $40(0-200)$ & $120(30-300)^{\star} \ddagger$ & $\begin{array}{l}\star 0.0001 \\
\neq 0.0004 \\
\$ 0.03\end{array}$ \\
\hline $\begin{array}{l}\text { PNTML (mS) } \\
\text { FD }\end{array}$ & $\begin{array}{l}2 \cdot 08(1 \cdot 5-3 \cdot 3) \dagger \\
1 \cdot 7(1 \cdot 1-2 \cdot 4)^{\star}\end{array}$ & $\begin{array}{l}2 \cdot 1(1 \cdot 75-2 \cdot 5) \\
1 \cdot 7(1 \cdot 1-2 \cdot 6) \ddagger\end{array}$ & $\begin{array}{l}2 \cdot 5(1 \cdot 7-5 \cdot 5) \dagger \\
1 \cdot 8(1 \cdot 1-3)\end{array}$ & $\begin{array}{l}2 \cdot 08(1 \cdot 4-2 \cdot 6) \\
1 \cdot 5(1 \cdot 1-1 \cdot 75)^{\star} \ddagger\end{array}$ & $\begin{array}{l}+0.0009 \\
\star 0.006 \\
+0.001\end{array}$ \\
\hline $\begin{array}{l}\text { AS (mA) } \\
\text { RS (mA) }\end{array}$ & $\begin{array}{r}4 \cdot 2(1 \cdot 7-18) \dagger \\
14 \cdot 9(4 \cdot 8-53) \dagger\end{array}$ & $\begin{array}{r}5(2 \cdot 6-11) \\
18(4 \cdot 8-40)\end{array}$ & $\begin{array}{l}7 \cdot 4(1 \cdot 6-39) \dagger \\
28 \cdot 4(4-99) \dagger\end{array}$ & $\begin{array}{l}4 \cdot 9(1 \cdot 5-13 \cdot 6) \\
23 \cdot 6(4 \cdot 7-67)\end{array}$ & $\begin{array}{l}+0.002 \\
+0.012 \\
+0.012\end{array}$ \\
\hline
\end{tabular}

TABLE III Results of resting pressure $(R P)$, voluntary contraction pressure (VCP), pudendal latencies $(P N T M L)$, anal canal $(A S)$ and rectal sensation $(R S)$ in multiple sclerosis (incontinent, MSI and continent, MSC), faecal incontinence without $M S(F I)$ and normal controls $(N C)$, excluding parous women (median (range))

\begin{tabular}{|c|c|c|c|c|c|}
\hline & $M S I$ & $M S C$ & $F I$ & $N C$ & $p$ \\
\hline $\begin{array}{l}\text { Number } \\
\mathrm{RP}\left(\mathrm{cm} \mathrm{H}_{2} \mathrm{O}\right) \\
\operatorname{VCP}\left(\mathrm{cm} \mathrm{H}_{2} \mathrm{O}\right)\end{array}$ & $\begin{array}{l}11 \\
80(40-100)^{\star} \\
20(0-100)^{\star} \dagger\end{array}$ & $\begin{array}{l}9 \\
80(30-140) \\
70(0-100) \ddagger\end{array}$ & $\begin{array}{l}23 \\
66(20-120) \\
90(20-172) \dagger\end{array}$ & $\begin{array}{l}55 \\
90(40-200)^{\star} \\
140(30-300)^{\star} \ddagger\end{array}$ & $\begin{array}{l}\star 0.005 \\
\star 0.0001 \\
\neq 0.002 \\
+0.001\end{array}$ \\
\hline $\begin{array}{l}\text { PNTML }(\mathrm{mS}) \\
\text { FD }\end{array}$ & $\begin{array}{l}2 \cdot 1(1 \cdot 7-3 \cdot 1) \\
1 \cdot 8(1 \cdot 35-2 \cdot 4)^{\star}\end{array}$ & $\begin{array}{l}2(1 \cdot 8-2 \cdot 4) \\
1 \cdot 8(1 \cdot 4-1 \cdot 9) \ddagger\end{array}$ & $\begin{array}{l}2 \cdot 4(1 \cdot 7-3 \cdot 3) \\
1 \cdot 7(1 \cdot 1-2 \cdot 3)\end{array}$ & $\begin{array}{l}2(1 \cdot 5-5 \cdot 3) \\
1 \cdot 45(1 \cdot 1-1 \cdot 7)^{\star} \ddagger\end{array}$ & $\begin{array}{l}\star 0.0002 \\
\pm 0.0004\end{array}$ \\
\hline $\begin{array}{l}\text { AS (mA) } \\
\text { RS (mA) }\end{array}$ & $\begin{array}{c}4 \cdot 9(2 \cdot 8-9 \cdot 4)^{\star} \\
13 \cdot 9(5 \cdot 6-53) \dagger\end{array}$ & $\begin{array}{c}5 \cdot 5(2 \cdot 6-11) \\
18(4 \cdot 8-39)\end{array}$ & $\begin{array}{c}7(2 \cdot 3-19 \cdot 1) \\
29 \cdot 9(14 \cdot 9-99 \cdot 9) \dagger\end{array}$ & $\begin{array}{c}5 \cdot 4(1 \cdot 5-13 \cdot 6) \\
23 \cdot 4(4 \cdot 7-67)\end{array}$ & t0.003 \\
\hline
\end{tabular}

the comparisons, which showed statistically significant differences.

Compared with the normal controls, the incontinent multiple sclerosis patients had significantly lower resting pressures, lower maximum voluntary contraction pressures, and higher fibre densities. Pudendal nerve terminal motor latencies, however, were normal. Comparing this group with the FI group the incontinent multiple sclerosis patients had higher resting pressures, shorter pudendal latencies, and unimpaired anal canal and rectal mucosal sensation. Comparing the multiple sclerosis continent group and the normal controls, the multiple sclerosis patients had significantly lower contraction pressures and increased fibre densities, but the resting anal pressures, although lower, were not significantly different.

The only difference shown by comparison of the multiple sclerosis continent and incontinent patients was that faecal incontinence was associated with a lower anal contraction pressure. When parous women were excluded from the analysis, the results of the comparison between the incontinent multiple sclerosis group and the controls were unchanged (Table III). Comparison of the MSI and FI groups on this analysis showed that resting anal pressures were reduced to a lesser extent in the nulliparous FI patients, and that these values were not significantly different between the two groups. Contraction pressures were significantly lower in the MSI group than in the FI group. Analysis of fibre density and pudendal nerve terminal motor latencies showed that both the MSI and MSC patients, and the FI patients have significantly increased fibre densities compared with controls but pudendal nerve terminal motor latencies in both the multiple sclerosis groups were normal, whereas they were increased in the FI patients. Considering the male and nulliparous multiple sclerosis patients only, no differences in any of the variables of pelvic floor function between the continent and the incontinent patients were seen; the reduction in contraction pressures seen in the whole MSI group were mainly because of the inclusion of parous women in this group.

\section{Discussion}

The problem of bowel dysfunction in multiple sclerosis has not been investigated to any great extent, and studies so far reported have contained only small numbers of patients. Swash et al studied 12 faecally incontinent multiple sclerosis patients and concluded that the incontinence was due to a combination of central lesions and coincidental pudendal nerve lesions associated with childbirth. ${ }^{9}$ They showed that fibre density in the external anal sphincter was increased in the parous patients (1.9) compared with the controls $(1.5)$ and nulliparous patients $(1 \cdot 7)$, which has been confirmed in this study, showing that multiple sclerosis alone has an effect on the peripheral external anal sphincter innervation. In this study fibre density was increased compared with controls whether parous women were included in the analysis or not. Swash et $a l^{9}$ also found that pudendal latencies to the external anal sphincter were 
normal in multiple sclerosis patients with incontinence, which contrasts with the considerable slowing of pudendal nerve conduction seen in idiopathic faecal incontinence, ${ }^{10}$ pointing to different pathophysiological mechanisms in these two groups of patients. The question remains, however, as to why multiple sclerosis patients have increased fibre density measurements in the external anal sphincter, suggesting peripheral nerve dysfunction. As these findings were seen in the nulliparous female and male analysis, they are not entirely a result of the damaging effects of childbirth on the pudendal nerves. It is possible that this could be explained by demyelination of the segment of the lower motor neurone between the anterior horn cell and its exit point from the spinal cord, a lesion that is known to occur in multiple sclerosis."

Anorectal sensory and sphincter pressures in multiple sclerosis have been investigated by Caruana $e t$ al $^{12}$ who studied 11 incontinent and 11 continent multiple sclerosis patients who had no bowel symptoms, thus differing from this study population. They showed decreased anal sphincter contraction pressures in both groups of multiple sclerosis patients, more noticeable in the incontinent group compared with controls, but normal resting anal pressures. The threshold of rectal sensation to an air filled balloon was increased in the multiple sclerosis patients suggesting impaired stretch receptor function in the pelvic floor, or central lesions.

This study has shown impaired external anal, and possibly internal anal sphincter function in patients with multiple sclerosis. The major contribution to resting anal canal pressure comes from the internal anal sphincter ${ }^{13}$ but some $15 \%$ is still accountable for by the external anal sphincter. In view of the fact that resting pressure in multiple sclerosis was not lowered as much as in FI, a condition that is thought in some cases to entail internal anal sphincter dysfunction, ${ }^{14}$ it is possible that the internal anal sphincter is, in fact, normal in multiple sclerosis. Indeed it would be difficult to explain why this autonomically innervated muscle should be affected in multiple sclerosis when no such dysfunction has been directly shown in this group of patients, although Glick et al ${ }^{15}$ proposed that a 'visceral neuropathy' existed in patients with multiple sclerosis and Weber t $\mathrm{ll}^{16}$ showed slowed colonic transit to radio-opaque shapes in 14 or 16 multiple sclerosis patients with bladder disturbances and constipation. No sensory abnormalities, either to an air filled balloon or in mucosal electrosensitivity were shown in the multiple sclerosis patients, in contrast with the sensory deficit in the anal canal and rectum seen in the incontinent non-multiple sclerosis patients, pointing to the importance of pudendal nerve damage in the causation of idiopathic neurogenic faecal incontinence, and that the pathophysiology of incontinence is different in multiple sclerosis.

A further point of interest is the similarity of the findings in the multiple sclerosis incontinent and multiple sclerosis continent groups, the only difference being that although contraction pressures were decreased in both groups compared with controls they were lower in the incontinent group. Both groups had increased external anal sphincter fibre densities without prolongation of pudendal nerve terminal motor latencies suggesting that it is a central lesion or lesions, at sites unknown, which determines whether a multiple sclerosis patient becomes incontinent, regardless of whether or not they have had children.

In conclusion, pelvic floor function is disturbed in multiple sclerosis irrespective of the patient's symptoms. This is mainly a result of lesions within the central nervous system although there is evidence, in addition, of damage to the peripheral motor innervation of the external anal sphincter. Pudendal nerve injury, associated with childbirth, may have an additive effect in some multiple sclerosis patients with incontinence.

Mr J S Jameson is supported by a grant from the Medical Research Council to Dr J J Misiewicz.

1 Miller H, Simpson CA, Yeates WK. Bladder dysfunction in multiple sclerosis. BMf 1965; 1: 1265-9.

2 Hinds JP, Eidelman BH, Wald A. Prevalence of bowel dysfunction in multiple sclerosis. A population survey. Gastroenterology 1990; 98: 1538-42.

3 Poser CM, Paty DW, Scheinberg L, et al. New diagnostic criteria for multiple sclerosis: guidelines for research criteria for multiple sclerosis: guidel

4 Kiff ES, Swash M. Normal proximal and delayed distal conduction in the pudendal nerves of patients with idiopathic (neurogenic) faecal incontinence. $\mathcal{F}$ Neurol Neurosurg Psychiatry 1984; 47: 820-3.

5 Neill $M E$, Swash $M$. Increased motor unit fibre density in the external anal sphincter muscle in ano-rectal incontinence: a single fibre EMG study. F Neurol Neurosurg Psychiatry 1980; 43: 343-7.

6 Bielefeldt K, Enck P, Erckenbrecht JF. Sensory and motor function in the maintenance of anal continence. Dis Colon Rectum 1990; 33: 674-8.

7 Miller R, Bartolo DC, Cervero F, Mortensen NJ. Differences in anal sensation in continent and incontinent patients with perineal descent. Int 7 Colorectal Dis 1989; 4: 45-9.

8 Rogers J, Henry MM, Misiewicz JJ. Combined sensory and motor deficit in primary neurogenic faecal incontinence. Gut 1987; 29: 5-9.

9 Swash M, Snooks SJ, Chalmers DH. Parity as a factor in incontinence in multiple sclerosis. Arch Neurol 1987; 44: $504-8$

10 Kiff ES, Swash M. Slowed conduction in the pudendal nerves in idiopathic (neurogenic) faecal incontinence. Br $\mathcal{F}$ Surg 1984; 71: $614-6$.

1 Mathews WB, Acheson ED, Batchelor JR. McAlpine's multiple sclerosis. New York: Churchill-Livingstone Inc, 1985: 358.

2 Caruana BJ, Wald A, Hinds JP, Eidelman BH. Anorectal sensory and motor function in neurogenic fecal incontinsencon mellitus. Gastroenterology 1991; 100: 465-70.

13 Frenckner B, Euler CV. Influence of pudendal block on the function of the anal sphincters. Gut 1975; 16: 482-9.

14 Speakman CT, Kamm MA. The internal anal sphincter - new insights into faecal incontinence. Gut 1991; 32: 345-6.
inteakman CT, Kamm MA. The internal anal sphincter

15 Glick ME, Meshkinpour H. Haldeman S, Bhatia NN, Bradley WE. Colonic dysfunction in multiple sclerosis. Gastroenterology 1982; 83: 1002-7.

16 Weber J, Grise P, Roquebert M, et al. Radiopaque markers transit and anorectal manometry in 16 patients with multiple sclerosis and urinary bladder dysfunction. Dis Colon Rectum 1987; 30: 95-100. 